\title{
FARKLI TAŞITLARDA KULLANILAN ÖN TAMPONLARIN DARBE EMİCİ ÖZELLİKLERİNINN ARAŞTIRILMASI
}

\author{
İbrahim YAVUZ1* ${ }^{*}$, Mustafa Çağdaş ERIK²
}

${ }^{1}$ Afyon Kocatepe Üniversitesi, Teknoloji Fakültesi, Otomotiv Mühendisliği Bölümü, Afyon, Türkiye

${ }^{2}$ Afyon Kocatepe Üniversitesi, Fen Bilimleri Enstitüsü, Otomotiv Mühendisliği Anabilim Dalı, Afyon, Türkiye

\begin{tabular}{ll}
\hline Anahtar Kelimeler & Öz \\
\hline Ön Tampon, & Trafik kazaları tüm dünyada olduğu gibi ülkemizde de çözülmeyi bekleyen önemli \\
Polimer Malzeme, & sosyal problemlerden biridir. Özellikle araç saylarının artması ile trafik kazaları da \\
Darbe Test, & sürekli artmaktadır. Bu sebeple taşıt imalatçlları tarafından, taşıtlarda aktif ve pasif \\
Enerji Absorbesi. & güvenlik olmak üzere birçok güvenlik tedbiri alınmaktadır. En sık karşılaşılan \\
& çarpışma türü taşıtların önden çarpma şeklinde meydana gelmektedir. Taşıtlarda \\
& bulunan tamponların görevi önden kazalarda kaza anındaki kinetik enerjiyi absorbe \\
& ederek taşıt içindeki yolcu ve sürücülerin en az hasarla kazayı atlatmasını \\
& sağlamaktır. Bu sebeple bu çalışmada, dört farklı otomobile ait olan ön tampon \\
& üretiminde kullanılan polimer malzemelerin darbe kuvvetine karşı enerji absorbe \\
& kabiliyetleri araştırılmıştır. Tampon malzemeleri EPDM (Etilen propilen) ve PP \\
& (Polipropilen)' dir. Bu malzemeler farklı kalınlıklarda ASTM D3763-02 standardına \\
& göre değerlendirilmişlerdir. Test sabit hızlarda ve farklı malzeme kalınlıklarında \\
& gerçekleştirilmiş olup, elde edilen bilgiler absorbe edilen enerji-uzama, gerilme-yer \\
değiştirme ve hız-zaman grafiklerinde gösterilmiştir. Yapılan testlerde H ve F & araçlarının ön tampon malzemelerinin darbe sönümleme kabiliyetlerinin diğer iki \\
& araçtan daha iyi olduğu görülmüştür. \\
\hline
\end{tabular}

\section{INVESTIGATION OF THE IMPACT ABSORBENT CHARACTERISTICS OF FRONT BUMPERS USED IN DIFFERENT VEHICLES}

Keywords
Front Bumper,
Polymer Material,
Impact Test,
Energy Absorption.

Alıntı / Cite Mühendislik Bilimleri ve Tasarım Dergisi, 9(3), 850-855.

\begin{abstract}
Traffic accidents are one of the important social problems waiting to be solved in our country as well as in the whole world. Especially with the increase in the number of vehicles, traffic accidents are constantly increasing. For this reason, many safety measures, including active and passive safety, are taken by vehicle manufacturers. The most common type of collision is the frontal collision of vehicles. The task of the bumpers in the vehicles is to absorb the kinetic energy at the time of the accident from the front and ensure that the passengers and drivers in the vehicle overcome the accident with the least damage. For this reason, in this study, the energy absorption capabilities of the polymers used in the production of front bumpers belonging to four different vehicles were investigated against the impact force. The materials used are PP (Polypropylene) and EPDM (Ethylene propylene). These materials are evaluated according to ASTM D3763-02 standard in different thicknesses. The test was carried out at constant speeds and different material thicknesses, and the information obtained was shown in the energy-strain, stressdisplacement and velocity-time graphs. In the tests performed, it was observed that the impact absorption capabilities of the front bumper materials of the $\mathrm{H}$ and $\mathrm{F}$ vehicles were better than the other two vehicles.
\end{abstract}

Yavuz, İ., Erik, M. Ç.., (2021). Farklı Taşıtlarda Kullanılan Ön Tamponların Darbe Emici Özelliklerinin Araştırılması,

\footnotetext{
* İlgili yazar / Corresponding author: iyavuz@aku.edu.tr, +90-505-522-2603
} 


\begin{tabular}{l|l|l}
\hline Yazar Kimliği / Author ID (ORCID Number) & \multicolumn{3}{|l}{ Makale Süreci / Article Process } \\
\hline İ. Yavuz, 0000-0002-4480-2342 & Başvuru Tarihi / Submission Date & 27.11 .2020 \\
M. Ç. Erik, 0000-0001-9219-2692 & Revizyon Tarihi / Revision Date & 14.06 .2021 \\
& Kabul Tarihi / Accepted Date & 14.06 .2021 \\
& Yayım Tarihi / Published Date & 21.09 .2021 \\
\hline
\end{tabular}

\section{Giriș (Introduction)}

Trafik kazaları, tüm dünyada olduğu gibi ülkemizde de çözülmesi gereken sosyal problemlerdir. Özellikle taşıt sayısının artması ile trafik kazaları da artan taşıt sayısına bağlı olarak artmaktadır. Dolayısı ile, taşıtlarda güvenliği arttırmak zorunlu hale gelmiştir (Serkan vd., 2018). Taşıtların tasarımında kazaların önlenmesi veya kaza esnasında oluşacak can veya mal kayıplarının en aza indirilmesi için yeni güvenlik sistemleri geliștirilmektedir. Bu teknolojiler pasif ve aktif güvenlik olarak iki sınıfa ayrılmaktadır. Pasif güvenlik taşıtların bir kazaya karışması durumunda, kazanın olumsuz etkilerini en aza indirmek amacıyla taşıtların üzerinde alınan hava yastıkları, çelik bariyerler gibi daha çok taşıt gövdesinde ve yapısal iyileștirmeler gibi tasarım değişikliklerini içermektedir. Aktif güvenlik sistemleri ise sürücünün kazaya karışmasını önlemek için taşıtların kontrol ve frenleme yeteneklerini iyileştirecek şekilde sistemlerin ve kaza ihtimalini tahmin edip, aracı bu sıkıntılı durumdan çıkarmaya çalışacak şekilde sürücüyü devre dışı bırakıp, devreye giren kontrol mekanizmalarını içerir (Öztürk, 2014).

Taşıtlarda güvenliğin yanında diğer önemli bir hususta sera gazı emisyonları standartlarıdır (Özer, 2016). Son yıllarda, otomotiv sektöründen, düşük sera gazı emisyon (CO2, NOx) salınımlı ve yakıt tüketimi olan araçların üretimi istenilmektedir.

Yakıt verimliliğini iyileștirme teknolojisi sınırlı olduğundan, otomobil parçalarının ağırlı̆̆ının azaltılması zorunluluk hale gelmiştir. Otomobil ağırlı̆ıının\% 1 azaltılmasının yakıt tüketimini $\% 0,7$ azalttığı bildirilmektedir (Joo vd., 2020; Errico vd., 2015; Hou vd., 2018; Park ve Park, 2018; Vaidya, 2011). Otomobil parçalarının ağırlı̆ıııın azaltılması, yapının optimizasyonu, bileşenlerin işlevselliğinin iyileştirilmesi ve hafif malzeme kullanılmasıyla sağlanabilir (Hou vd., 2018; Liu vd., 2013; Xong vd., 2018; Zuo vd., 2011; Bai vd., 2017).

Yapılan çalışmalarda araçların üzerinde bulunan bazı parçaların toplam ağırlıkları fazla olarak tespit edilmiş ve alternatif malzeme arayışına girilmiştir. Bu malzemelerin başında polimerler gelmektedir.

Polimer malzemelerin (Plastikler) endüstride sıklıkla kullanılanları "Mühendislik Plastikleri" adı altında değerlendirilir. Mühendislik plastikleri her geçen gün teknolojinin istek ve taleplerine karşı çeşitlenmekte ve geliştirilmektedir. Fakat otomotiv sektöründe mühendislik plastiklerinin kullanımı 100 yıl kadar önce olsa da yüksek üretim maliyetleri nedeniyle uzun bir süre boyunca yaygınlaşamamıștır. Günümüzde ise polimer teknolojisindeki gelişmelere paralel olarak ucuzlayan üretim yöntemleri sayesinde özellikle termoplastikler otomotiv sektöründe epeyce yüksek bir kullanım oranına sahip olmuşlardır (Küçükoğlu vd. 2020).

Otomotiv ve diğer birçok alanda kullanılan plastikler herhangi bir şekilde, durumda ya da cismin dışarıdan bir müdahalesi sonucu darbeye maruz kalabilirler. Örneğin herhangi bir taşıt karayolunda gider ken yola aniden çıkan yaya, hayvan vb. engele çarpması sonucu tamponda hasar olușabilir (Erik, 2019).

Malzemenin üzerine gelen darbenin şiddetini ölçen birden fazla darbe test yöntemi ve cihazı vardır. Bu çalışmada hava basıncı ile çalışan darbe test cihazı kullanılmıștır. Darbeler hızlı ve yavaş olmak üzere 2'ye ayrılırlar. Fakat birçok kaynağın belirttıği üzere yavaş darbe ile hızlı darbe tanımlarının net bir ayrımının olmadığını göstermektedir. Yine de bir tanımlama yapılacak ise; malzemelerin rijitlik, kütle ve fiziksel özelliklerine bağlı kalmak șartıyla sabit hedef malzemeye çarpan diğer malzemenin hızı 1-10 m/s arasında ise yavaş darbe, $10 \mathrm{~m} / \mathrm{s}$ ve üzeri bir hıza sahipse hızlı darbe denmektedir (Sayer, 2009).

Lee ve arkadaşları (1999) yaptıkları çalışmada darbe testleri genel olarak yüksek hız ve düşük hız olmak üzere iki ayrı sınıfta incelemişlerdir. Yüksek hızlı darbe testlerinde yapının tümü darbeye tepki gösterecek yeterli zamanı bulamayacağından zarar görmektedir. Düşük hızlı darbe testlerinde ise temas süresi yeteri kadar uzun olduğu için yapının tamamı darbeye tepki gösterebilmektedir. Böylece darbe enerjisini elastik olarak absorbe etmesine olanak sağlamaktadır.

Agrawal ve arkadaşları (2014) yaptıkları çalışmada fiberle güçlendirilmiş polimer matriksli kompozit bit malzemede darbe kuvvetinin yapmıș olduğu etkiyi daha geniş bir alandaki davranışını incelemişlerdir. Benzer bir çalışmada ise Fındık ve Tarim (2003) Polimer kompozitlerin balistik darbe verimliliği üzerine yaptıkları araştırmada bazı polimer bazlı kompozit malzemelerin darbe verimliliği deneysel olarak incelenmiştir. Bu 
çalışmada dört farklı araca ait polimer malzemelerin düşük hızda darbe testleri yapılarak elde edilen sonuçların kıyaslaması yapılmıştır. Testlerde enerji sönümleme kabiliyetleri incelenmiş ve test sonuçları kıyaslanmıştır.

\section{Materyal ve Yöntem (Material and Method)}

Bu çalışmada PP ve EPDM katkılı 4 farklı aracın ön tamponundan 100x100 mm ölçülerinde dikdörtgen şekilli numuneler hazırlanmıştır. Numunelerin boyutları ASTM 3763-02'de bahsedildiği üzere hazırlanmıştır. Darbe deneylerinde Instron-Dynatup 9250 HV darbe test cihazı kullanılarak darbe dayanımları test edilmiştir (Şekil 1).

Test cihazı, serbest ağırlık düşürme prensibine göre çalışan yer tipi, yüksek hızlı ve sistem kontrollü bir darbe cihazıdır. İmpuls sinyal şartlandırma birimine, impuls veri toplama kartına ve veri elde etme yazılımına sahip olması cihazı sistem kontrollü olma özelliği sağlamaktadır (Esendemir ve Karaca 2019) .

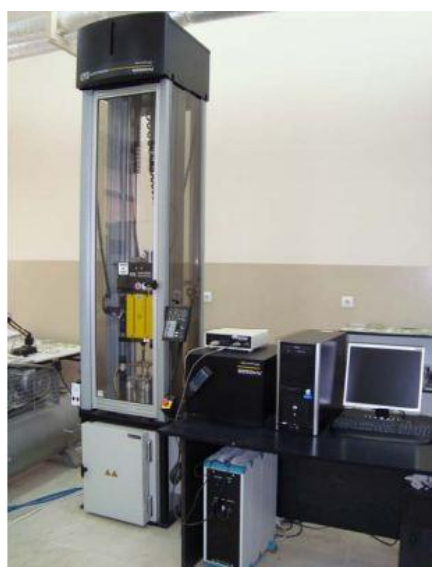

Şekil1. Instron-Dynatup 9250 HV darbe dayanım test cihazı (Instron-Dynatup 9250 HV impact tester)

Cihaz darbe için ekstradan bir uygulayacağı bir kuvvet istendiğinde bunu üzerindeki yaylar vasıtası ile gerçekleştirebilmektedir. Yaylar darbe cihazına ekstradan 2,6 ile 826 Joule arasında bir enerji verebilmektedir. Ayrıca sisteme ek ağırlıklarda ilave edilerek toplamda 1603 Joule'lük bir enerji elde edilebilmektedir (Sayer 2009).

Cihazda yay desteği olmadan ağırlı̆̆ın düşebileceği maksimum yükseklik 1,25 m'dir. Yay devreye girer ise simüle ettiği yükseklik 20,4 m’ye kadar çıkmaktadır. Sistemin yay enerjisini kullanmadan çıkabileceği maksimum hız 5 m/s'dir. Yay enerjisi kullanıldığında ise bu hız 20 m/s hıza kadar çıkabilmektedir. Bu hıza çıktığında cihazda meydana gelen titreme malzemeye uygulanan darbe şiddetinin az da olsa etkilenmesine sebep olmaktadır.

\subsection{Numunelerin Hazırlanması (Preparation of Samples)}

Deneyde kullanılan malzemeler ile kalınlıkları Tablo 1'de verilmiştir. Piyasada kullanımda olan dört farklı aracın tomponlarından standart haline getirilerek (boyutsal, kalınlıklar üzerinde işlem yapılmamıştır) numuneler çıkartılmıştır. Deneyin amacı taşıtları kıyaslamak olduğu için numuneler üzerinde (Kalınlıklar üzerinde) herhangi bir işlem yapılmamıştır.

Tablo 1. Malzemelerin kalınlıkları(Thickness of materials)

\begin{tabular}{|c|c|c|c|c|}
\hline Deney Numunesi & F Aracı & H Aracı & R Aracı & T Aracı \\
\hline Kalınlık (mm) & 3 & 3 & 4 & 4 \\
\hline
\end{tabular}

Darbe testlerinde kullanılacak olan malzemeler 100x100 mm ölçülerinde olacak şekilde kıl testere ile kesildi. Her araç tipinden 3'er adet farklı hızlarda deneyler yapılmıştır. Çekme ve sertlik için ise ayrı ayrı testlere tabi tutuldu. Araçların tampon malzemesi PP+EPDM olduğu tamponların üzerindeki açıklayıcı kısaltmalardan tespit edilmiş olup Tablo 2' de ayrıntılı bir şekilde tanımlanmıştır.

Tablo 2. Deneyde kullanılan ön tampon malzemelerinin özellikleri (Properties of the front bumper materials used in the experiment)

\begin{tabular}{|c|c|c|c|c|}
\hline Malzeme & $\begin{array}{c}\text { Yoğunluk } \\
\text { (g/cm3) }\end{array}$ & $\begin{array}{c}\text { Kopma } \\
\text { Uzaması (\%) }\end{array}$ & $\begin{array}{c}\text { Elastisite } \\
\text { Modülü (MPa) }\end{array}$ & $\begin{array}{c}\text { Kopma } \\
\text { Mukavemeti (MPa) }\end{array}$ \\
\hline EPDM & 1,4 & 300 & - & 5 \\
\hline PP & 0,9 & 6 & 1325 & 34 \\
\hline
\end{tabular}




\section{Deneysel Sonuçlar (Experimental Results)}

Dört farklı araca ait olan polimer malzemelerin darbe testleri $3 \mathrm{~m} / \mathrm{s}$ sabit hızda yapılmıştır. Bu hızlardaki kuvvetyer değiștirme, hız- zaman ve absorbe edilen enerji-yer değiștirme grafikleri incelenmiştir. Deneylerin tamamı $25^{\circ} \mathrm{C}$ sicaklıkta yapılmıștır.

\subsection{Kuvvet-Yer değiştirme Grafiklerinin İncelenmesi (Force-Displacement Graph of The Vehicles)}

Şekil 2'deki ölçümler vurucu uç malzemeye dokunduğu andaki kuvvetler baz alınmıştır. Darbe enerjisinin oluşturduğu kuvveti sönümleyerek uzayan deney numuneleri sırayla H taşıtı, F taşıtı, R taşıtı ve T taşıtıdır.

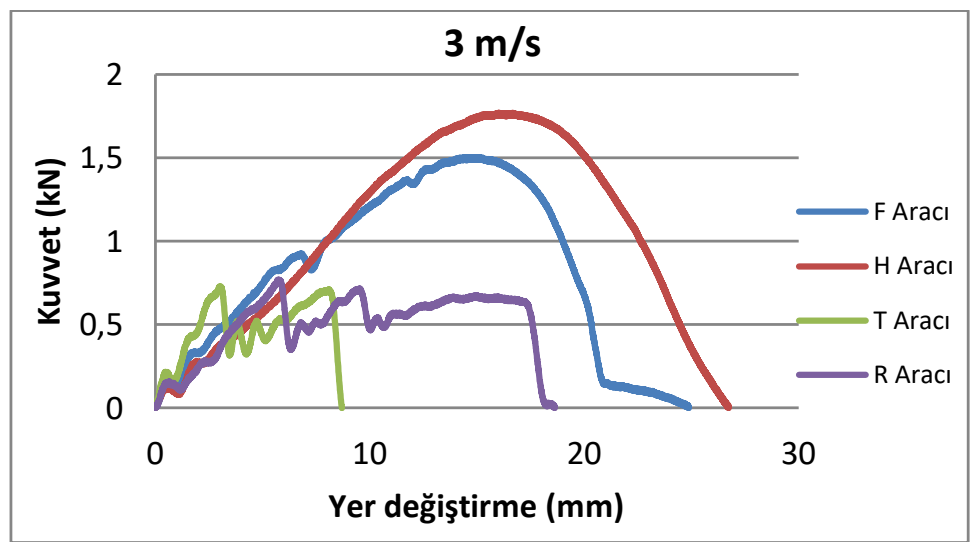

Şekil 2. Teste tabi tutulan taşıtların $3 \mathrm{~m} / \mathrm{s}$ hızdaki kuvvet - yer değiştirme grafiği (Force-displacement graph of the vehicles under test at a speed of $3 \mathrm{~m} / \mathrm{s}$ )

Yer değiştirme miktarları ise sırayla 26,73 mm, 24,84 mm, 18,56 mm ve 8,67 mm'dir. Sadece H taşıtı 3 m/s hızdaki kuvveti tam olarak sönümlemiştir.

\subsection{Taşıtlara ait Hız-Zaman Grafiklerinin İncelenmesi (Velocity-Time Graph of Tested Vehicles)}

Şekil 3'de görülen grafikte ilk sırayı H taşıtına ait olup $3 \mathrm{~m} / \mathrm{s}^{\prime}$ lik hızı $1 \mathrm{~m} / \mathrm{s}$ hıza kadar düşürmüştür. İkinci sırada ise $\mathrm{F}$ taşıtı gelmektedir. $\mathrm{F}$ taşıtında ise $1 \mathrm{~m} / \mathrm{s}^{\prime}$ lik bir hız düşümünün gerçekleştiği görülmektedir. T ve $\mathrm{R}$ taşıtlarına ait olan numunelerde ise birbirlerine yakın sonuçlar elde edilmiş olup, yaklaşık olarak 0,5 m/s 'lik hız düşümünün olduğu görülmüştür.

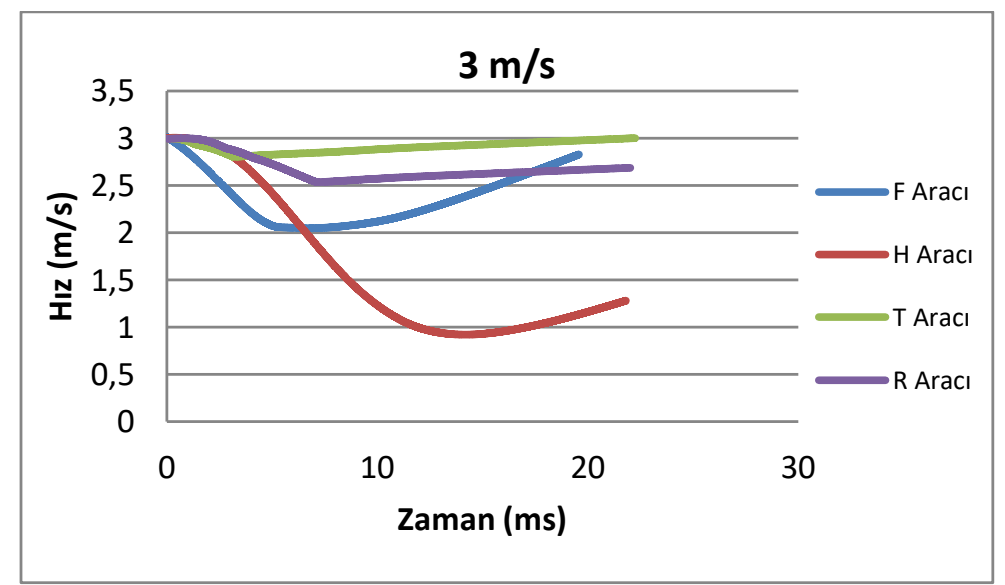

Şekil 3. Teste tabi tutulan tașıtların $3 \mathrm{~m} / \mathrm{s}$ hızdaki hız-zaman grafiği (Velocity-time graph of tested vehicles at $3 \mathrm{~m} / \mathrm{s}$ )

\subsection{Absorbe Edilen Enerji-Yer değiştirme Grafiklerinin İncelenmesi (Absorbed Energy-Displacement Graph of Tested Vehicles)}

Şekil 4'de görüldüğü üzere enerjiyi en iyi absorbe eden araç $\mathrm{H}$ aracıdır. H aracının emdiği enerji miktarı ise 27,75 J' dür. F aracı 20,95 J, R aracı 9,33J, T aracı 4,10 J enerji absorbe etmiştir. 


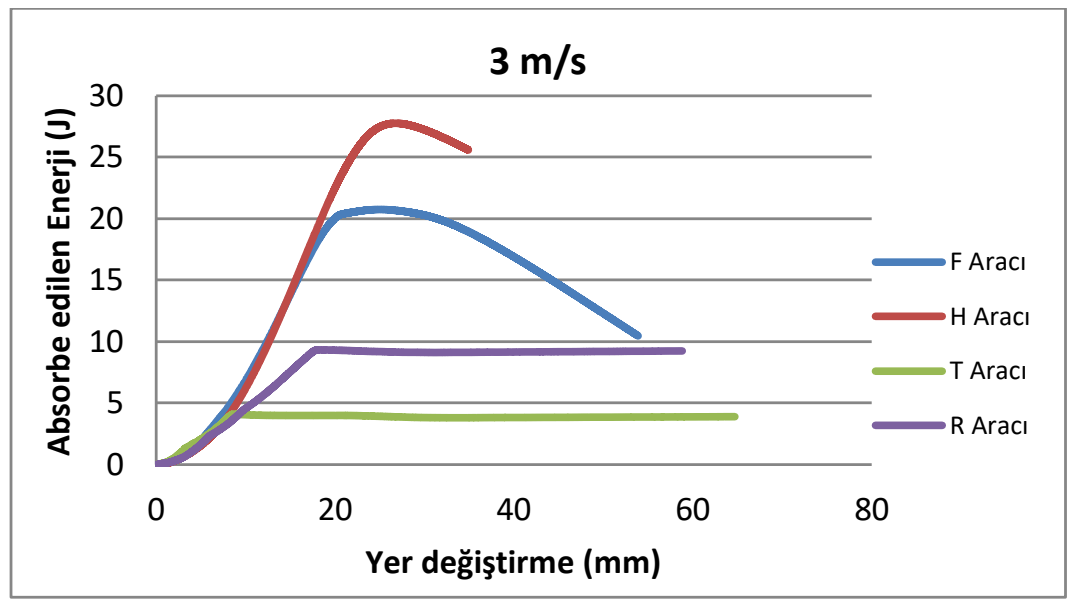

Şekil 4. Test edilen taşıtların $3 \mathrm{~m} / \mathrm{s}$ hızdaki absorbe edilen enerji-yer değiștirme grafiği (Absorbed energy-displacement graph of tested vehicles at $3 \mathrm{~m} / \mathrm{s}$ )

Malzeme üzerinde yapılan çalışmalar arttıkça tampon malzemelerindeki enerji sönümleme kabiliyetlerinin geliștiği söylenebilinir. Numunelerin deney sonucundaki görüntüleri Şekil 5’te verilmiștir.

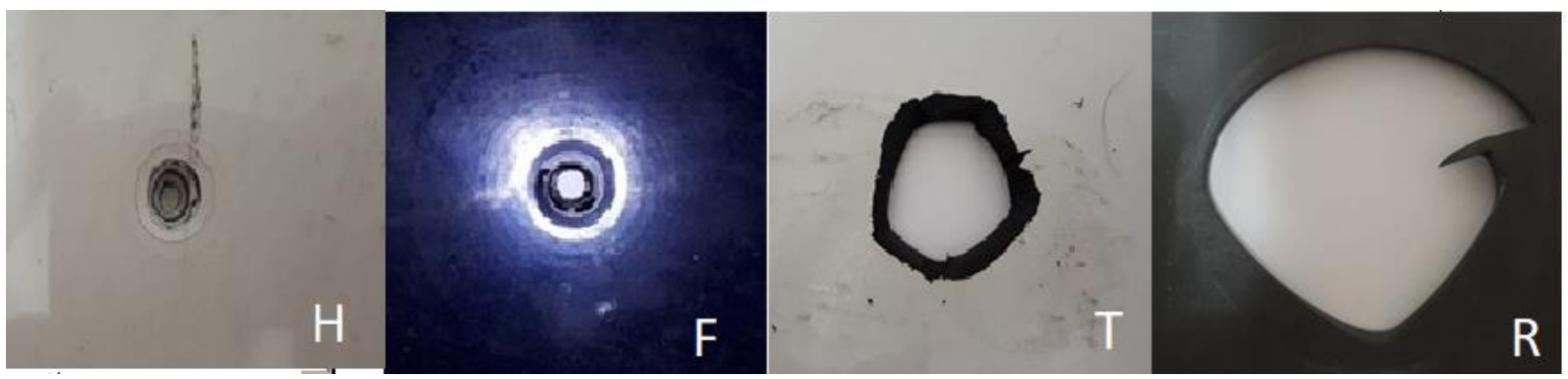

Şekil 5. Numunelerin darbe testi sonrası görüntüleri (Images of the samples after the impact test)

\section{Sonuç ve Tartışma (Result and Discussion)}

Taşıtların ön tamponları pasif güvenlik sistemleri içerisinde en önemli parçalardan biridir. Bu sebeple bu çalıșmada darbe enerjilerinin sönümleme kabiliyetleri incelenmiștir. Bunun için sabit çarpma hızında ve dört farklı otomobil üreticisinin ürettiği araçların ön tampon malzemeleri kullanılmıştır. Test $25^{\circ} \mathrm{C}$ sabit sıcaklıkta tutulan bir ortamda gerçekleştirilmiştir.

Sabit hızda yapılan testler sonucunda kuvvet ve sönümleme kabiliyeti olarak en iyi ön tampon malzemesinin $\mathrm{H}$ aracına ait olduğu anlaşılmıștır. Yapılan testlerde " $\mathrm{H}$ " ve " $\mathrm{F}$ " araçlarının ön tampon malzemelerinin darbe sönümleme kabiliyetlerinin diğer iki araçtan daha iyi olduğu görülmüştür. Bu taşıtlara ait tamponların daha sünek olmasından kaynaklandığı düşünülmektedir. Darbe deneyi sonucu resimlerinden de anlaşılacağı gibi en gevrek malzeme ise " $\mathrm{R}$ " taşıtına ait malzeme olduğu sonucuna varılmıştır.

Benzer şekilde yine test esnasında delici sistemin hızının en aza inmesine sebep olan nunume yine " $\mathrm{H}$ " aracına ait olandır. Bu sonuçtan da herhangibir kaza esnasında darbeleri absorbe edebilecek en iyi sönümleme kabiliyetine sahip olan malzeme olduğu anlaşılmaktadır.

\section{Çıkar Çatışması (Conflict of Interest)}

Yazarlar tarafından herhangi bir çıkar çatışması beyan edilmemiştir. No conflict of interest was declared by the authors.

\section{Kaynaklar (References)}

Agrawal, Singh and Sarkar. 2014. Impact damage on fibre-reinforced polymer matrix composite. Journal of Composite Materials, 48: 317-332.

Bai, J., Li, Y., Zuo, W., 2017. Cross-sectional shape optimisation for thin-walled beam crashworthiness with stamping constraints using genetic algorithm Int J Vehicle Design, 73, 76-95

Erik N. C., 2019. Otomotiv Gövde Imalatinda Kullanilan Polimer Malzemelerin Enerji Sönümleme Yeteneklerinin İncelenmesi, Afyon Kocatepe Üniversitesi Fen Bilimleri Enstitüsü Yüksek Lisans Tezi 
Errico F, Ranza L., 2015. Guidelines for the market competitiveness of sustainable lightweight design by magnesium solution: a new Life Cycle Assessment integrated approach. IMA's 72nd World Magnesium Conference: International Magnesium Association, 22-7.

Esendemir Ü., Karaca. H., 2019. Düşük Hızlı Darbe Yüküne Maruz Kompozit Plakalara Asidik Ortamın Etkisi, Mühendislik Bilimleri ve Tasarım Dergisi 7(1), 26 - 33.

Findik F., Tarim N., 2003, Ballistic impact efficiency of polymer composites, Composite Structures, 61, 187-192

Hou, W., Xu, X., Wang, H. L., 2018. Tong Bending behavior of single hat-shaped composite T-joints under out-of-plane loading for lightweight automobile structures J Reinforc Plast Compos, 0731684418764608.

Joo, S. J., Yu, M.H., Kim, W.S., J.W. Lee, Kim H.S., 2020. Design and manufacture of automotive composite front bumper assemble component considering interfacial bond characteristics between over-molded chopped glass fiber polypropylene and continuous glass fiber polypropylene composite Compos Struct, 236, 111849

Küçükoğlu A., Özyapı G., Acar A., Bağrıyanık A.O., Çolpan O., Çelik H., Yağcı Y.E., 2020. Çok Bileşenli Kalıplama Yöntemine Uygun Sürekli Elyaflı Termoplastik Kompozit Akü Taşıyıcı Parçasının Geliştirilmesi, Mühendislik Bilimleri ve Tasarım Dergisi 8(4), $1223-1235$

Lee S.M, Cheon J.S., LM Y.T.i 1999. Experimental and numerical study of the impact behavior of SMC plates. Composite Stractures, 47: 551-561

Liu , Q., Lin, Y., Zong , Z., G., Sun , Li, Q., 2013. Lightweight design of carbon twill weave fabric composite body structure for electric vehicle Compos Struct, 97, 231-238.

Özel S., Karagöz, Selçuk, Turan, H., Beytüt, Turan, M., K., 2018. Taşıt Tampon Malzemesi Olarak Alüminyum Alaşımlarının Kullanılmasının Taşıt Çarpışma Performansına Etkisi,1 st International Symposium on Light Alloys and Composite Materials (ISLAC'18).

Özer H., CanY., Güçlü H., Karen İ., Yazici M., 2016. Bursa Termoplastik Kompozit Malzeme Ve Sentaktik Köpük Esasli Sandviç Yapilardan Çok Hafif Tampon Kirişi Ve Darbe Sönümleyici Geliştirilmesi, 8. Otomotiv Teknolojileri Kongresi, 23 - 24 Mayıs

Öztürk İ., Kaya N., Öztürk F., 2014. Otomobil Ön Tampon Çarpişma Simülasyonu ve Optimizasyonu” Otomotiv Teknolojileri Kongresi

Park, G., Park, H., 2018. Structural design and test of automobile bonnet with natural flax composite through impact damage analysis Compos Struct, 184, 800-806.

Sayer M. 2009. Hibrit Kompozitlerin Darbe Davranıșının İncelenmesi. Doktora Tezi. Pamukkale Üniversitesi, Fen Bilimleri Ensitisü, Denizli.

Vaidya, U., 2011. Composites for automotive, truck and mass transit: materials, design, manufacturing: DEStech Publications Inc .

Xiong, F., Wang, D., Ma Z., Chen, S., Lv T, Lu F. 2018. Structure-material integrated multi-objective lightweight design of the front end structure of automobile body. Struct Multidiscipl Optimizat, 57:829-47.

Zuo W., Xu T., Zhang H., Xu T., 2011. Fast structural optimization with frequency constraints by genetic algorithm using adaptive eigenvalue reanalysis methods Struct Multidiscipl Optimizat, 43, 799-810. 